\title{
Natural diversity of potato (Solanum tuberosum) invertases
}

\author{
Astrid M Draffehn, Sebastian Meller, Li Li, Christiane Gebhardt*
}

\begin{abstract}
Background: Invertases are ubiquitous enzymes that irreversibly cleave sucrose into fructose and glucose. Plant invertases play important roles in carbohydrate metabolism, plant development, and biotic and abiotic stress responses. In potato (Solanum tuberosum), invertases are involved in 'cold-induced sweetening' of tubers, an adaptive response to cold stress, which negatively affects the quality of potato chips and French fries. Linkage and association studies have identified quantitative trait loci (QTL) for tuber sugar content and chip quality that colocalize with three independent potato invertase loci, which together encode five invertase genes. The role of natural allelic variation of these genes in controlling the variation of tuber sugar content in different genotypes is unknown.

Results: For functional studies on natural variants of five potato invertase genes we cloned and sequenced 193 full-length cDNAs from six heterozygous individuals (three tetraploid and three diploid). Eleven, thirteen, ten, twelve and nine different cDNA alleles were obtained for the genes Pain-1, InvGE, InvGF, InvCD141 and InvCD111, respectively. Allelic cDNA sequences differed from each other by 4 to $9 \%$, and most were genotype specific. Additional variation was identified by single nucleotide polymorphism (SNP) analysis in an association-mapping population of 219 tetraploid individuals. Haplotype modeling revealed two to three major haplotypes besides a larger number of minor frequency haplotypes. CDNA alleles associated with chip quality, tuber starch content and starch yield were identified.

Conclusions: Very high natural allelic variation was uncovered in a set of five potato invertase genes. This variability is a consequence of the cultivated potato's reproductive biology. Some of the structural variation found might underlie functional variation that influences important agronomic traits such as tuber sugar content. The associations found between specific invertase alleles and chip quality, tuber starch content and starch yield will facilitate the selection of superior potato genotypes in breeding programs.
\end{abstract}

\section{Background}

Invertases are ubiquitous enzymes that irreversibly cleave sucrose into the reducing sugars fructose and glucose. Plant invertases not only play an important role in the partitioning of carbon between source tissue (photosynthetic leaves) and heterotrophic sink tissues such as seeds, tubers and fruits, they also function in plant development and in responses to biotic and abiotic stress. Three types of invertase isoenzymes, which are encoded by small gene families, are regularly found in plants. Cell wall-bound acidic invertases cleave sucrose in the apoplastic space (apoplastic invertases). Soluble

\footnotetext{
* Correspondence: gebhardt@mpiz-koeln.mpg.de

Max-Planck Institute for Plant Breeding Research, Carl von Linné Weg 10, 50829 Köln, Germany
}

acid invertases are located in the vacuole (vacuolar invertases), whereas soluble neutral invertases are located in the cytoplasm $[1,2]$.

In the potato (Solanum tuberosum), carbon is stored as starch polymers in tubers. Besides starch, tubers also contain small amounts of sucrose, glucose and fructose. The amounts of starch and sugars present in tubers depend on the genotype and on environmental factors. Storage at low temperature (e.g. $4^{\circ} \mathrm{C}$ ) for several weeks leads to conversion of a small fraction of starch into sugars in tubers, with consequent accumulation of glucose and fructose, in particular [3,4]. This phenomenon of 'cold-induced sweetening' is an adaptive response to cold stress, as sugars have long been known to have an osmoprotective function in plants [5]. Invertases, 
together with other proteins, play a role in determining the tuber sugar content before and during cold storage. Invertase activity is present in tubers and increases during cold storage [6-8]. Transcripts of vacuolar invertase accumulate in the tubers upon cold storage [9-11] and invertase antisense inhibition changes the hexose to sucrose ratio in the tubers [10]. The content of the reducing sugars glucose and fructose in tubers is an important criterion of quality for the potato processing industry. During deep frying at high temperatures, reducing sugars and amino acids undergo a non-enzymatic Maillard reaction, which results in a dark brown color and inferior taste of potato chips or French fries due to polyphenol formation [12,13]. With increasing tuber sugar content, the chip color changes from light yellow to brown or even black. Although the enzymatic and biochemical steps in the interconversion between starch and sugars are well known in plants in general and potato in particular, the triggering and the regulation of cold-induced sweetening in potato is not fully understood $[3,4,14]$. In addition, the impact of natural variation in potato genes involved in carbohydrate metabolism on the quantitative variation of tuber starch and sugar content among different genotypes is completely unknown.

Genetic mapping of quantitative trait loci (QTL) for tuber starch and sugar content on the one hand $[15,16]$ and localization of genes that function in carbohydrate metabolism and transport on the other [17] have pointed to a number of candidate genes, which roughly colocalize with QTL for tuber starch and sugar content [18]. Among these are three independent loci encoding invertase genes. Potato cDNAs encoding apoplastic and vacuolar invertases have been cloned and characterized previously $[10,11,19,20]$. Using invertase cDNA sequences as molecular markers, these three potato invertase loci have been mapped [17]. The Pain-1 locus on chromosome III encodes a vacuolar invertase, whereas the loci $I n v_{a p}-a$ and $I n v_{a p}-b$ on chromosomes $\mathrm{X}$ and IX, respectively, encode apoplastic invertases [17]. Two tandemly duplicated genes, InvGE and InvGF, encoding apoplastic invertases have been identified in one genomic fragment of $9 \mathrm{~kb}[21]$. InvGE and InvGF are orthologous to the closely related tomato invertase genes LIN5 and LIN7, respectively, which are also tandemly duplicated and located on tomato chromosome 9 [22]. The $I n v_{a p}-b$ locus maps to the orthologous position on potato chromosome IX. In view of the colinearity of the genomes of potato and tomato [23], InvGE/InvGF can both be assigned to the Inv $v_{a p}-b$ locus. The locus Inv $v_{a p}-a$ on chromosome $\mathrm{X}$ was mapped with the same cDNA probe 'pCD141' [20] as Inv $v_{a p}-b$, and is orthologous to a tomato locus on chromosome 10 encoding the tandemly duplicated invertase genes LIN6 and LIN8
[22]. Genomic sequences of the potato $\operatorname{In} v_{a p}-a$ and Pain-1 loci have not been reported.

Association mapping in populations of tetraploid potato varieties and breeding clones has revealed 'singlestrand conformation polymorphisms' (SSCPs) [24] in invertase genes at all three loci, which were associated with tuber starch content, and/or chip color $[25,26]$. Most significant were associations with SSCP markers derived from the Pain-1 gene on chromosome III [25]. These marker-trait associations are either direct (i.e. allelic variants of the invertase gene itself are causal for the phenotypic variation) or indirect (genes that are physically linked but unrelated to the invertase gene are responsible for the QTL) in effect. In the latter case, the association observed at an invertase locus is the result of linkage disequilibrium between the invertase gene and other, unknown genes in the same haplotype block [27]. Unfortunately, neither QTL linkage mapping down to single-gene resolution [28] nor high-resolution association mapping using thousands of individuals for complex traits such as tuber starch content and chip color is practicable in the cultivated potato. An alternative approach is the direct functional analysis of invertase allelic variants to elucidate their roles in determining variation in tuber starch and sugar content. This requires the cloning and characterization of full-length invertase cDNA alleles from representative potato genotypes, and the identification of cDNA alleles that correspond to the associated SSCP markers. Here we report the results of such a study.

\section{Methods}

\section{Plant material}

Invertase alleles were cloned from the tetraploid cultivars Satina, Diana and Theresa, and from the diploid $S$. tuberosum lines H82.337/49 (P18), H80.696/4 (P40) and H81.839/1 (P54) [29]. The tetraploid genotypes were selected from 34 varieties included as standards in the association mapping population 'ALL' described in [25], because they possess invertase markers that are associated with tuber starch content (TSC), starch yield (TSY), and chip quality in autumn after harvest (CQA) and after cold storage (CQS) (Table 1). The diploid genotypes were the parents of the mapping populations used to map cold-sweetening QTL [16]. Plants were grown in pots in the greenhouse (day temperature 20$24^{\circ} \mathrm{C}$; night temperature $18^{\circ} \mathrm{C}$; additional light from 6 am to $9 \mathrm{pm}$ ) or in a Saran-house under natural light and temperature conditions from May to September. Leaves and flowers were harvested throughout the growing season. Tubers were harvested from mature plants and stored at $4^{\circ} \mathrm{C}$ in the dark. Genomic DNAs from 219 members of the association mapping population ALL were used for SNP genotyping. This population consists 
Table 1 Presence/absence in cvs. Satina, Diana and Theresa of invertase markers associated with tuber traits

\begin{tabular}{|c|c|c|c|c|c|c|c|}
\hline Locus & Chromosome & Marker fragment & Association with & Polarity of effect & Satina & Diana & Theresa \\
\hline \multirow[t]{5}{*}{ Pain-1 } & III & Pain 1-9a 1,3 & TSC, TSY, CQA, CQS & $\uparrow \uparrow$ & yes & yes & no \\
\hline & & Pain 1-8c 1,3 & TSC, TSY, CQA, CQS & $\uparrow \uparrow$ & yes & yes & no \\
\hline & & Pain $1-5 c^{1,3}$ & TSC, TSY, CQA, CQS & $\uparrow$ & no & yes & no \\
\hline & & Pain1-5d ${ }^{3}$ & TSC & $\uparrow$ & yes & no & no \\
\hline & & Pain1-5b ${ }^{3}$ & TSC, CQS & $\downarrow$ & no & no & yes \\
\hline \multirow[t]{2}{*}{$\ln v_{a p}-b$} & IX & $\ln V G E-6 f^{2,4}$ & CQA, CQS & $\uparrow \uparrow$ & yes & yes & yes \\
\hline & & $\ln v G F-4 d^{2,5}$ & CQA, CQS & $\uparrow$ & yes & yes & yes \\
\hline $\ln v_{a p}-a$ & $x$ & $p C D 141-3 c^{3}$ & TSC, CQA, CQS & $\downarrow$ & yes & no & no \\
\hline
\end{tabular}

${ }^{1}$ SSCP markers Pain1-9a, Pain 1-8c and Pain 1-5c are in strong linkage disequilibrium with each other [25]

${ }^{2}$ Markers InvGE-6f and InvGF-4d are in nearly complete linkage disequilibrium with each other [26].

${ }^{3}$ SSCP (single strand conformation polymorphism) marker [25].

${ }^{4}$ SCAR (sequence characterized amplified region) marker [26].

${ }^{5}$ ASA (allele specific amplification) marker [26].

of 34 standard varieties and 209 breeding clones from three potato breeding companies. The ALL population has been phenotyped for tuber yield (TY, [dt/ha]), starch content (TSC, [\%]), starch yield (TSY, [dt/ha]), and chip quality after harvest in autumn (CQA, score from 1 to 9) and after cold storage at $4^{\circ} \mathrm{C}(\mathrm{CQS}$, score from 1 to 9) $[25]$.

\section{RNA extraction and cDNA synthesis}

Total RNA was extracted from leaves and flowers using the ToTally RNA Isolation Kit (Ambion, Cambridgeshire, UK) following the supplier's protocol. Total RNA was extracted from tuber tissue powdered in liquid nitrogen, using the Plant RNA Isolation Kit from Invitrogen (Karlsruhe, Germany) following the supplier's protocol. Tuber RNA was further purified by high-salt precipitation to remove polysaccharides and by lithium chloride precipitation to remove low-molecular-weight RNA. The RNA solution was adjusted to $1 \mathrm{~mL}$ by adding RNase-free water, mixed with $250 \mu$ lisopropanol and $250 \mu \mathrm{l}$ high salt solution (1.2 M sodium citrate, 0.8 $\mathrm{M} \mathrm{NaCl}$ ) and incubated on ice for $2 \mathrm{~h}$. RNA was recovered by centrifugation at $13,000 \mathrm{rpm}$ for $30 \mathrm{~min}$ at $4^{\circ} \mathrm{C}$. The pellet was rinsed with $70 \%$ ethanol, and centrifuged at $13000 \mathrm{rpm}$ for $5 \mathrm{~min}$ at $4^{\circ} \mathrm{C}$. After removing the ethanol, the pellet was air-dried and dissolved in RNase-free water at a minimum concentration of $200 \mathrm{ng}$ total RNA per $\mu$ l. High-molecular-weight RNA was precipitated by mixing with 0.5 volumes of $5 \mathrm{M} \mathrm{LiCl}$ and incubating on ice overnight at $4^{\circ} \mathrm{C}$. RNA was collected by centrifugation as above, rinsed with $70 \%$ ethanol, dried and dissolved in 20-50 $\mu$ l RNase-free water depending on pellet size. All RNA samples were further purified using the DNA-free ${ }^{\mathrm{Tx} \mathrm{K}}$ Kit (Ambion). RNA concentration and quality were analyzed by measuring the $A_{260} \mathrm{~nm} / A_{280} \mathrm{~nm}$ $\left(1.8\right.$ - 2.0) and $A_{260} \mathrm{~nm} / \mathrm{A}_{230 \mathrm{~nm}}(2-3)$ ratios using a Nanodrop ND-1000 spectrophotometer (Peclab,
Erlangen, Germany). RNA integrity was tested on $1 \%$ agarose gels loaded with 300-500 ng of total RNA. Total RNA was stored at $-80^{\circ} \mathrm{C}$. First-strand cDNA was synthesized according to the supplier's protocol from $2.0 \mu \mathrm{g}$ of total RNA, using $200 \mathrm{U}$ of Superscript ${ }^{\mathrm{TM}}$ II Reverse Transcriptase (Invitrogen) per reaction and 500 ng of oligo(dT) ${ }_{16-18}$ (Roche, Mannheim, Germany) as primers. First-strand cDNA was treated with RNase $\mathrm{H}$ (Roche, Mannheim, Germany) for $20 \mathrm{~min}$ at $37^{\circ} \mathrm{C}$. Firststrand cDNA ( $1 \mu$ l per reaction) was then used for allele amplification and cloning.

\section{Invertase cDNA allele amplification, cloning and sequencing}

Primers spanning the start and stop codons of the invertase genes (Table 2) were designed based on the sequences of GenBank accession numbers L29099, X70368 (Pain-1), AJ133765 (InvGE and InvGF), Z21486 (InvCD111) and Z22645 (InvCD141). Pain-1 alleles were amplified using as template first-strand cDNA from tubers stored for 25 days at $4^{\circ} \mathrm{C}$. InvGE and $I n v G F$ alleles were amplified from first-strand cDNA templates obtained from leaves and flowers. InvCD111 and InvCD141 alleles were amplified from leaf cDNA templates. Oligonucleotides were purchased from Invitrogen (Karlsruhe, Germany), Sigma-Aldrich Chemie (Taufkirchen, Germany) and Operon Biotechnologies (Köln, Germany). Polymerase chain reactions (PCR) (annealing temperatures $55-65^{\circ} \mathrm{C}, 30-50$ cycles) were performed using the Fast Start High Fidelity PCR System (Roche, Mannheim, Germany) or KOD Hot Start DNA Polymerase (Novagen, Darmstadt, Germany) according to the supplier's protocols. PCR products were purified with the High Pure PCR Purification Kit (Roche, Mannheim, Germany) and ligated into the $\mathrm{pGEM}^{\circ}-\mathrm{T} / \mathrm{T}$ Easy vector (Promega, Mannheim, Germany) following the supplier's 
Table 2 PCR primers used for cDNA allele cloning and amplicon sequencing, product sizes, annealing temperatures.

\begin{tabular}{|c|c|c|c|c|}
\hline Gene & Ampli-con & Forward $(\mathrm{F})$ and reverse $(\mathrm{R})$ primers $5^{\prime}$ to $3^{\prime}$ & Length [bp] & $\mathrm{T}_{\mathrm{a}}\left[\mathrm{C}^{\circ}\right]$ \\
\hline \multirow[t]{4}{*}{ Pain-1 } & CDNA & $\begin{array}{l}\text { F: ATGGCCACGCAGTACC } \\
\text { R: GATGAATTACAAGTCTTGCAAGGG }\end{array}$ & 1920 & 55 \\
\hline & Exon 1 & $\begin{array}{l}\text { F: ATGGCCACGCAGTACC } \\
\text { R: GTTGAAAATGGTAAGCAGTTC }\end{array}$ & 360 & 52 \\
\hline & Exon 3 & $\begin{array}{l}\text { F: CACAAGGGATGGTATCATC } \\
\text { R: CCCATCCCTTCTGCAG }\end{array}$ & 861 & 51 \\
\hline & Exon 7 & $\begin{array}{l}\text { F: CACTCAATTGTGGAGAGCTTTG } \\
\text { R. CAAGTCTTGCAAGGGGAAGG }\end{array}$ & 201 & 59 \\
\hline \multirow[t]{3}{*}{ InVGE } & CDNA & $\begin{array}{l}\text { F: ATGGAATTATTTATGAAAAGCTCTTCTCTITGGGGGT } \\
\text { R: TTAGTGCATCTTAGGTACATCCATGCTCCAAGC }\end{array}$ & 1761 & 55 \\
\hline & Exon 1 & $\begin{array}{l}\text { F: GCTCTTCTCTITGGGGTITAG } \\
\text { R: TTAGGAGGTTGAAAATGAAAAC }\end{array}$ & 199 & 56 \\
\hline & Exon 6 & $\begin{array}{l}\text { F: GATAACTCAGTAGTGGAGAGTITG } \\
\text { R: GTGCATCTAAGTACATCCATG }\end{array}$ & & 56 \\
\hline $\ln v G F$ & CDNA & $\begin{array}{l}\text { F: ATGGATTATTCATCTAATTCTCGTTGGGCTTTGCCAG } \\
\text { R: TCAATATTGTATCTTAGCTTTGCCCATACTCCATGC }\end{array}$ & 1743 & 55 \\
\hline \multirow[t]{3}{*}{$\ln v C D 141$} & CDNA & $\begin{array}{l}\text { F: ATGGAGATTTAAAGAAGATCTTCTTCTCTTTGGGTT } \\
\text { R: CTAGTGCAACTTGCATTAGCCATGCTCCAAGC }\end{array}$ & 1746 & 55 \\
\hline & Exon 3 & $\begin{array}{l}\text { F: GGTCCAATGTATTACAATGGAG } \\
\text { R: GCAACTGTGATTCCTITGATTTC }\end{array}$ & 1023 & 56 \\
\hline & Exon 4 & $\begin{array}{l}\text { F: GAAGTGATTTTCTCATTCACAAG } \\
\text { R: CTTGAGGCATCAGAACACATAAG }\end{array}$ & 246 & 56 \\
\hline $\operatorname{lnvCD111}$ & CDNA & $\begin{array}{l}\text { F: ATGGATTGTTTAAAAAAGTCTTCTC } \\
\text { R: TCAATAAGAAGAGTGACCAAATGACCAATTCA }\end{array}$ & 1767 & 55 \\
\hline
\end{tabular}

protocols. Competent cells of E. coli strains DH5 $\alpha$ and DH10B (MAX Efficiency ${ }^{\odot} \mathrm{DH}^{\mathrm{rm}}{ }^{\mathrm{TM}}$ and ElectroMAX ${ }^{\mathrm{sm}}$ $\mathrm{DH}_{10 \mathrm{~B}^{\mathrm{TM}}}$ competent cells from Invitrogen, Karlsruhe, Germany) were transformed with recombinant plasmids [30]. Transformed strains were cultured according to standard methods [31]. Plasmid DNA was isolated with Plasmid Isolation Mini or Midi Kits (Qiagen, Hilden, Germany) and sequenced by the DNA Core Facility at the Max-Planck Institute for Plant Breeding Research on Applied Biosystems (Weiterstadt, Germany) ABI PRISM 377, 3100 and 3730 sequencers, using BigDye terminator (v3.1) chemistry. Premixed reagents were from Applied Biosystems. SNPs were identified in multiple sequence alignments (http://multalin.toulouse.inra.fr/multalin/multalin.html). Due to the large number of cDNAs sequenced, most variants were represented at least two times in independent PCRs primed with first-strand cDNA from the same genotype. cDNA alleles were then defined based on the consensus sequences of all clones obtained from an individual genotype. In some cases, the number of full-length cDNA sequences per genotype was low (Table 3). Eleven alleles (InvGE-Db, InvGE-Sb, InvGF-Te, InvGF-Sb, InvCD141-Sa, InvCD141-Dd2, InvCD141-Td2, InvCD111-Sb, InvCD111-Sc, InvCD111Ta, InvCD111-P54d; see Tables S3, S4, S5 and S6 in additional files 1, 2, 3 and 4) were therefore defined based on a single cDNA sequence.

\section{Invertase genomic sequences}

The BAC (bacterial artificial chromosome) libraries BA and $\mathrm{BC}$, both constructed from high-molecular-weight genomic DNA of the diploid, heterozygous genotype P6/ 210 and arrayed on high density filters, were screened by filter hybridization with labeled probes for cDNAs Pain-1 [10] and $p C D 141$ [20] as described [32,33]. Positive BACs were confirmed by gene-specific PCR using primers as described above and Southern gel-blot hybridization. Complete BACs were custom sequenced by Eurofins MWG Operon (Ebersberg, Germany) using a 454 platform [34]. In addition, the genes Pain-1 and InvCD141 were custom sequenced (GATC Biotech, Konstanz, Germany) by primer walking on the BACs using the dideoxy chain-termination method [35]. Sequencing of the Pain-1 gene by primer walking was performed on the BAC selected for complete sequencing, whereas the gene InvCD141 was sequenced using BAC BC37c23. BAC sequences were annotated using the Apollo Genome Annotation and Curation Tool, version 1.9.8 [36].

\section{Phylogenetic tree construction}

Phylogenetic trees were generated using the maximum parsimony method based on a Clustal W amino acid alignment [37] of all invertase sequences integrated in the MEGA 4 software [38]. In all, 1000 bootstrapping runs were performed to obtain an estimate of the reliability of each branchpoint. 
Table 3 Summary of invertase cDNA allele cloning and SNP identification

No. of CDNA alleles identified per genotype (No. of full-length clones sequenced)

\section{Total No of different \\ number alleles (nucleic acid sequence)}

$\begin{array}{lll}\begin{array}{l}\text { No of } \\ \text { different }\end{array} & \text { No of } & \text { No of } \\ \text { SNP's } & \text { amino }\end{array}$

amino acid

sequences identified acid

changes

\begin{tabular}{|c|c|c|c|c|c|c|c|c|c|c|c|}
\hline Gene & Satina & Diana & Theresa & P40 & P54 & P18 & & & & & \\
\hline Pain-1 & $2(9)$ & $3(16)$ & $2(8)$ & $2(8)$ & $1(6)$ & $2(7)$ & $12(54)$ & 11 & 6 & 78 & 35 \\
\hline $\ln v G E$ & $4(10)$ & $3(8)$ & 4 (19) & $2(8)$ & $2(5)$ & $2(9)$ & 17 (59) & 13 & 12 & 137 & 53 \\
\hline $\ln v G F$ & $4(14)$ & $2(4)$ & $2(4)$ & $2(4)$ & $2(10)$ & $1(2)$ & $13(38)$ & 10 & 9 & 97 & 26 \\
\hline InvCD141 & $3(6)$ & $2(5)$ & $3(6)$ & $1(2)$ & $2(4)$ & $2(5)$ & $13(28)$ & 12 & 11 & 102 & 32 \\
\hline InvCD111 & $3(5)$ & $1(1)$ & $2(4)$ & $1(1)$ & $2(3)$ & $0(0)$ & $9(14)$ & 9 & 8 & 65 & 36 \\
\hline $\begin{array}{l}\text { Total } \\
\text { number }\end{array}$ & $16(44)$ & $11(34)$ & $13(41)$ & $8(23)$ & $9(28)$ & $7(23)$ & 64 (193) & 55 & 46 & 479 & 182 \\
\hline
\end{tabular}

\section{SNP genotyping}

Amplicons were generated from genomic DNAs of the heterozygous individuals of the ALL population with locus-specific primers (Table 2). The amplicons were purified with ExoSAP-IT ${ }^{\bullet}$ (USB, Cleveland, USA) and custom sequenced at the Core Facility for DNA Analysis of the Max-Planck Institute for Plant Breeding Research. The dideoxy chain-termination sequencing method was employed using an ABI PRISM Dye Terminator Cycle Sequencing Ready Reaction Kit and an ABI PRISM 3730 automated DNA Sequencer (Applied Biosystems, Weiterstadt, Germany). SNPs were identified by sequence alignment and visual examination of the sequence trace files for overlapping base-calling peaks. In each tetraploid individual bi-allelic SNPs were assigned to one of five allelic states (two homozygous and three heterozygous). The SNP allele dosage in heterozygous individuals (1:3, 2:2 or 3:1) was estimated from the relative heights of the overlapping base-calling peaks, both manually and with the Data Acquisition and Analysis Software DAx (Van Mierlo Software Consultancy, Eindhoven, The Netherlands). Pyrosequencing [39] was carried out on a PSQ 96 system (Biotage AB, Uppsala, Sweden) using the PSQ 96 SNP Reagent Kit according to the manufacturer's protocol. For pyrosequencing of the Pain1_SNP1544 alleles, the following primers were used to generate an amplicon of 252 bp: Forward : 5'-GGACCATTTGGTGTCGTTGT-3', reverse: 5'-(biotin) TCTTCCTCCTTGAGCAAAGC-3'. The sequencing primer was 5'-CGTTGTAATTGCTGATCA-3'.

\section{Haplotyping}

Within the SATlotyper (v.1.0.5) software [40] the SAT solver MiniSat_v1.14_cygwin was used to model haplotypes from unphased SNP data scored in the ALL population. Individuals with missing data for one or more SNPs in the set chosen for haplotyping and individuals with suboptimal quality of the amplicon sequence were excluded from haplotype analysis.

\section{Association test}

SNPs were tested for association with the phenotypic values using the general linear model (GLM) procedure in SPSS 15.0 (SPSS GmbH Software, Munich, Germany). The model used was

$$
\mathrm{y}^{*}=\text { origin }+ \text { marker }+ \text { error }
$$

where $y^{*}$ stands for the adjusted phenotypic means [25]. Origin is a factor (fixed) with four classes to identify the origin of each genotype in the ALL population from one of three breeding companies or from the standard varieties [25]. Marker is a factor (fixed) with five levels, corresponding to the five SNP allele dosages: 0 for allele absent, 1, 2, 3 and 4 for allele present in simplex, duplex, triplex or quadruplex dosage. Population structure has been evaluated and described in [25].

\section{Results}

Genomic structure of the invertase loci Pain-1 and Invap-a Whereas the genomic organization of the tandemly duplicated genes $I n v G E$ and $I n v G F$ at the $I n v_{a p}-b$ locus on chromosome IX is already known [21], no genomic sequences of the loci Pain-1 and Inv $v_{a p}-a$ have been reported. We therefore isolated, sequenced and annotated the BAC clones BC149o15 (HQ197978) and BC163115 (HQ197979), which were selected from BAC libraries based on cross-hybridization with Pain-1 and InvCD141 probes. In addition to 454 sequencing of whole BACs, the genes Pain-1 and InvCD141 were also sequenced by the dideoxy chain-termination method and primer walking. $\mathrm{BC} 149 \mathrm{o} 15$ contained one full-length copy of the Pain-1 gene. The Pain-1 sequences obtained from the same BAC by two different sequencing techniques (454 and Sanger sequencing) differed by a sixnucleotide insertion in intron 2. The Pain-1 gene consists of seven exons and six introns and is around $4 \mathrm{kbp}$ long (Figure 1). The BAC clone BC163115 contained two tandemly duplicated invertase genes, InvCD111 and 
InvCD141, which corresponded to the cDNA clones pCD111 and pCD141 [20]. The two genes, 5 and 4.5 $\mathrm{kbp}$ in size, are separated by $7.3 \mathrm{kbp}$ and each consists of six exons and five introns (Figure 1). Sanger sequencing of InvCD141 in a third BAC (BC37c23) revealed a gap of around $1 \mathrm{kbp}$ in the assembly of the 454 sequences in intron 2. Besides that, the two sequences differed by five nucleotides. The full annotation of BACs BC149o15 and BC163115 is shown in Table S1 in additional file 5. The individual genomic sequences of Pain1, InvCD141 and InvCD111 are available as GenBank accessions HQ110080, HQ110081 and HQ197977, respectively.

Natural diversity of Pain-1 CDNA alleles

Fifty-four full-length cDNA clones were sequenced from tubers of the tetraploid varieties Satina, Diana and Theresa, and the diploid genotypes P18, P40 and P54 that had been stored in the cold. Sequence comparisons identified eleven different cDNA alleles that translated into six amino acid sequences (Table 3). Fifty-eight single-nucleotide polymorphisms (SNPs) were detected when the eleven cDNA alleles were aligned. The inclusion of three soluble acid invertase sequences recovered from the NCBI database (accessions AAA50305 = Stpain1_a from cv Russet Burbank [11], ACC93585 = Stpain1_c from cv Kufri Chipsona and AAQ17074 = Stpain1_b from an unknown genotype) in the alignment uncovered sixteen additional SNPs. Sequencing of exons 1,3 and 7 of Pain-1 in the 34 standard varieties included in the association mapping population ALL identified four further SNPs. The total of 78 SNPs included one tri-allelic SNP and resulted in amino acid changes at 35 positions, corresponding to $5.5 \%$ of the deduced Pain-1 protein sequence (Table 3, Table S2 in additional file 6, Figure S1 in additional file 7). Phylogenetic analysis of the nucleic acid sequences (not shown) separated the cDNA alleles into four similarity groups $a, b, c$ and $d$. The group $d$ alleles from the diploid genotype $\mathrm{P} 40$ were most divergent from the others (see Table S2 in additional file 6). In order to identify cDNA alleles corresponding to the SSCP markers associated with the tuber traits (Table 1), and to detect any novel SNP-trait associations, we genotyped the ALL

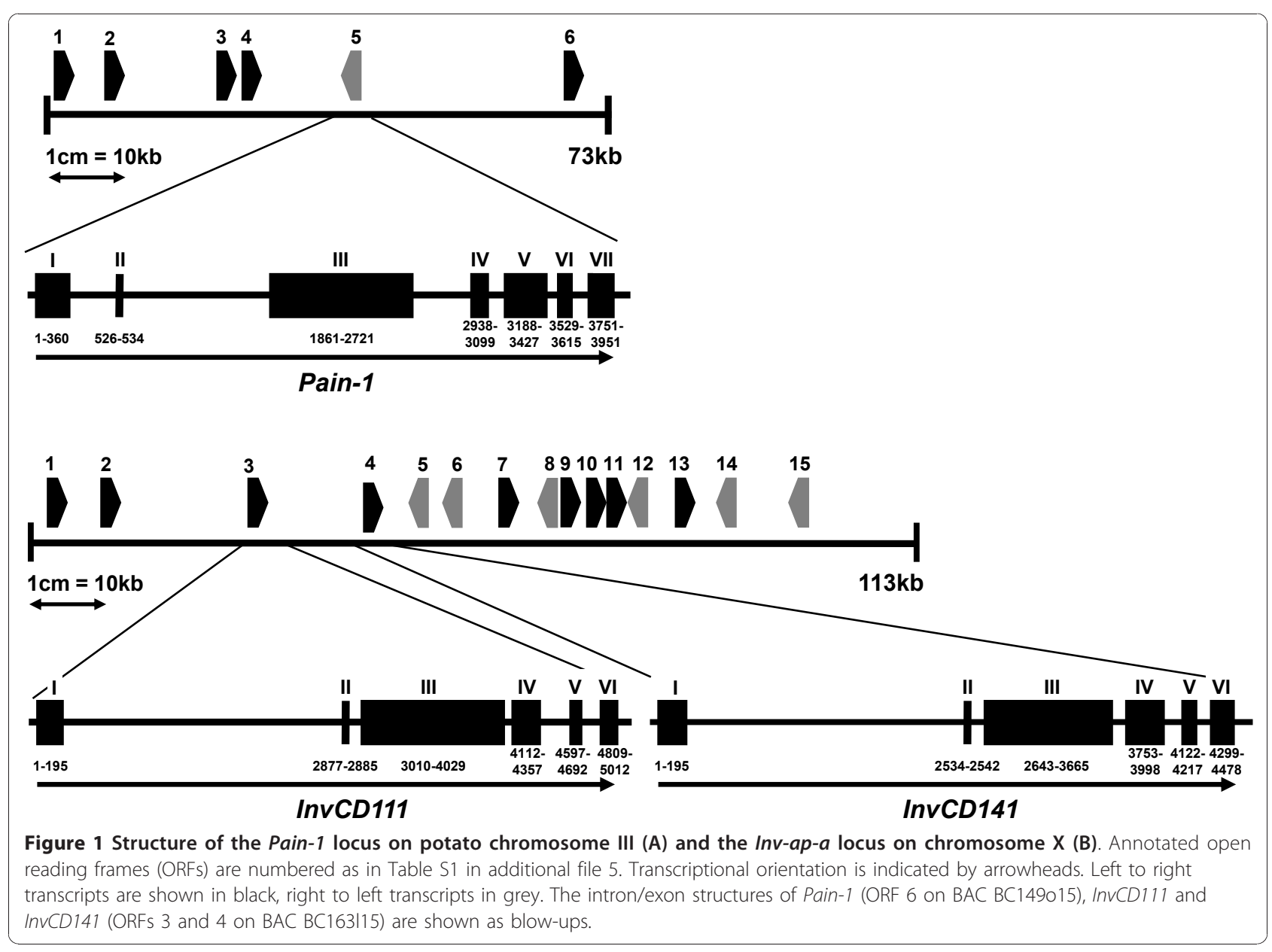


population for 15 SNPs in exon 3 of Pain-1 by amplicon sequencing, and for SNP1544 in exon 5 by pyrosequencing. These sixteen SNPs included diagnostic SNP alleles for groups $a, b, c$ and $d$ and for some individual alleles, i.e. one of the two alternative nucleotides was specific for an allele group or an individual allele (Table $\mathrm{S} 2$ in additional file 6). The SNP alleles $\mathrm{C}_{552}, \mathrm{~A}_{718}, \mathrm{~A}_{1544}$ and $\mathrm{T}_{741}$ were diagnostic for allele group $a, \mathrm{~A}_{528}$ for group $b, \mathrm{C}_{777}$ and $\mathrm{G}_{1068}$ for group $c$, and $\mathrm{T}_{591}$ and $\mathrm{G}_{637}$ for group $d$. Five SNPs present in exon 3 of the cDNA alleles were not detected in the corresponding amplicon sequences (SNPs 534, 723, 834, 852, 927). Conversely, four additional SNPs absent in the cDNA alleles were detected and scored in the amplicon sequences of the ALL population (SNPs 639, 825, 888, 943). The best correspondence between presence/absence of SNP alleles and the associated SSCP markers in the ALL population was found for the SNP alleles in group $a$ (Table 4). The SNP alleles $\mathrm{C}_{552}$ and $\mathrm{A}_{718}$ corresponded most closely to the SSCP marker Pain1-8c, $\mathrm{A}_{1544}$ to Pain1-9a, and the alleles $\mathrm{T}_{741}$ and $\mathrm{C}_{1143}$ were correlated with Pain1-5d. A 1544 was also weakly correlated with Pain1-5c. None of the SNPs corresponded to SSCP marker Pain1-5b. The 16 SNPs were also tested for association with the tuber traits TSC, TY, TSY, CQA and CQS. SNP alleles $C_{552}, A_{718}$ and $A_{1544}$ were positively associated with chip quality, tuber starch content and starch yield (lighter chip color, higher tuber starch content and starch yield, Table 5), as were the corresponding SSCP markers Pain1-8c and Pain1-9a [25]. The weak association of SSCP marker Pain1-5d with tuber starch content was confirmed by the corresponding SNP allele $\mathrm{T}_{741}$ (Table 5). The six genotypes used for cDNA cloning represent only a fraction of the genetic diversity of invertases in S. tuberosum. To obtain more comprehensive information on the number and frequency of Pain-1 haplotypes distributed in populations of tetraploid, heterozygous cultivars used in breeding programs, we selected eleven SNPs, which were diagnostic for allele groups $a$ (SNPs 552, 718 and 1544), $b$

Table 4 Similarity of distribution in the ALL population between associated Pain-1 SSCP markers and Pain-1 SNP alleles.

\begin{tabular}{|c|c|c|c|c|c|c|}
\hline \multirow[b]{2}{*}{$\begin{array}{l}\text { SSCP } \\
\text { marker }\end{array}$} & \multicolumn{5}{|c|}{ SNP alleles in group $a$} & \multirow{2}{*}{$\begin{array}{l}\text { Control allele in group } \\
\text { c } \\
G_{1068}\end{array}$} \\
\hline & $C_{552}$ & $A_{718}$ & $A_{1544}$ & $\mathrm{~T}_{741}$ & $C_{1143}$ & \\
\hline Pain 1-9a & $\begin{array}{l}0.63 \\
1\end{array}$ & 0.59 & 0.79 & 0.29 & 0.30 & 0.20 \\
\hline Pain 1-8c & 0.79 & 0.73 & 0.54 & 0.32 & 0.33 & 0.16 \\
\hline Pain 1-5c & 0.36 & 0.32 & 0.50 & 0.07 & 0.06 & 0.17 \\
\hline Pain 1-5b & 0.01 & 0.01 & 0.00 & 0.02 & 0.01 & 0.34 \\
\hline Pain 1-5d & 0.47 & 0.51 & 0.44 & 0.62 & 0.65 & 0.07 \\
\hline
\end{tabular}

1 Jaccard similarity measure
(SNP528), $c$ (SNPs 612 and 1068) and $d$ (SNPs 612 and 637), a novel allele $x$ not found among the cDNA clones (SNP 825), and the individual alleles $\mathrm{Sa}$ (SNP741), P18b (SNP1050) and Stpain1-a (SNP639 from cv Russet Burbank). Haplotypes were modeled using SATlotyper [40], a software that infers haplotypes from unphased SNP data in heterozygous polyploids. Fifteen haplotype models with frequencies higher than $1 \%$ were obtained based on eleven SNPs scored in 189 individuals of the ALL population (Table 6). The haplotypes $A, B$ and $C$ with frequencies higher than $10 \%$ accounted for $60 \%$ of all chromosomes in the population $(4 \times 189=756)$, whereas $35 \%$ were accounted for by 12 haplotypes with frequencies between $1 \%$ and $10 \%$. Among the latter were five haplotypes that included the associated SNP alleles $C_{552}, A_{718}, A_{1544}$ and $\mathrm{T}_{741}$. Five haplotype models were verified by corresponding cDNA clones, whereas the remaining ten haplotypes were novel (Table 6).

\section{Natural diversity of InvGE and InvGF CDNA alleles at the $\ln v_{a p}-b$ locus}

Fifty-nine $I n v G E$ and thirty-eight $I n \nu G F$ full-length cDNAs were cloned from leaf and flower tissue of the three tetraploid and the three diploid genotypes (Table 3), and subsequently sequenced. In contrast to the reported flowerspecific expression of $\operatorname{Inv} G F$ [21], we found that $I n v G F$ was expressed also in leaves. The expression level in leaves was genotype dependent (data not shown).

Comparative sequence analysis of the InvGE cDNAs identified 13 different cDNA alleles encoding 12 amino acid sequences (Table 3, Tables S3 and S4 in additional files 1 and 2). Alignment of the InvGE cDNAs and InvGE from accession AJ133765 (cv Saturna, StinvGE-c) [21] identified 133 SNPs (two of them tri-allelic) and two insertions/deletions (indels) of one codon each. Sequencing of the amplicons of exons 1 and 6 in the 34 standard varieties uncovered two additional SNPs. The 135 SNPs plus the two indels resulted in 53 amino acid changes, corresponding to $9.1 \%$ of the deduced InvGE protein sequence (Figure S2 in additional file 8). Grouping of the cDNA sequences according to similarity resulted in six groups (Table S3 in additional file 1). Group $a$ was the most divergent and group $d$ the most heterogeneous with many allele-specific SNPs. The Ta allele apparently resulted from recombination with allele $S d$. It had been shown previously [26] that Histidine 368 (His368) corresponds to the associated markers InvGE$6 f$ and InvGF-4d, which are in high linkage disequilibrium with each other due to the close physical linkage between InvGE and InvGF. The SNP allele $A_{1103}$ coding for His368 was specific for allele group $a$ (Table S3 in additional file 1). The cDNA alleles in InvGE group $a$ therefore corresponded to the marker InvGE-6f. Amplicon sequencing of exon 3 of gene InvGE proved difficult 
Table 5 Associations of invertase SNP alleles with chip quality (CQA, CQS), tuber starch content (TSC) and/or starch yield (TSY).

\begin{tabular}{|c|c|c|c|c|c|c|}
\hline Invertase SNP allele & $\begin{array}{l}\text { Invertase allele or allele } \\
\text { group }\end{array}$ & $\begin{array}{l}\text { SNP allele } \\
\text { frequency }\end{array}$ & CQA $F^{1}$ & CQS F & TSC $F$ & TSY $F$ \\
\hline Pain1- $A_{718}\left(C_{552}\right)^{2}$ & $a$ & 0.04 & $3.421^{*} \uparrow$ & $\begin{array}{c}8.161^{* * *} \\
\uparrow\end{array}$ & $8.344^{* * *} \uparrow$ & $\begin{array}{c}6.053^{* *} \\
\uparrow\end{array}$ \\
\hline Pain 1- $A_{1544}$ & $a$ & 0.06 & ns & $3.947^{*} \uparrow$ & $\begin{array}{c}10.683^{* * *} \\
\uparrow\end{array}$ & $\begin{array}{c}5.656^{* *} \\
\uparrow\end{array}$ \\
\hline Pain 1-T 741 & $a$ & 0.03 & ns & ns & $2.649^{*} \uparrow$ & $2.923^{*} \uparrow$ \\
\hline InvGE- $A_{85}\left(A_{86}\right)$ & $a, d$ & 0.30 & ns & ns & $5.006^{* *} \uparrow$ & $\begin{array}{c}4.044^{* *} \\
\uparrow\end{array}$ \\
\hline $\operatorname{lnvGE-G_{95}(G_{106})}$ & a & 0.06 & ns & $4.032^{*} \uparrow$ & ns & ns \\
\hline $\begin{array}{l}\operatorname{lnvCD} 141, T_{543}\left(A_{280}, T_{288,} T_{339}, A_{630}, C_{1030}, G_{1031}\right. \\
\left.T_{1096}\right)\end{array}$ & Sa & 0.14 & $\begin{array}{c}5.615^{* *} \\
\downarrow\end{array}$ & $3.850^{*} \downarrow$ & $6.125^{* *} \downarrow$ & ns \\
\hline InvCD141-G765 & e & 0.27 & ns & $4.596^{* *} \uparrow$ & $3.949^{* *} \uparrow$ & $2.706^{*} \uparrow$ \\
\hline
\end{tabular}

${ }^{1} F$ value; the $p$ value is indicated as $*(p<0.05),{ }^{*}(p<0.01)$ or ${ }^{* *}(p<0.001)$; the arrow indicates the direction of the effect, upwards for a positive (better chip quality, higher starch content, higher starch yield), downwards for a negative effect of the SNP allele, respectively.

${ }^{2}$ SNP alleles shown in parentheses are in strong linkage disequilibrium with the allele for which the association has been shown, and therefore display similar associations.

due to the presence of the two indels. We therefore amplified and sequenced exon 1 in the ALL population and scored eleven SNPs, which were tested for association with the tuber traits. SNP allele $G_{95}$, which is diagnostic for alleles $S a$ and $D a$, showed a weak association with CQS, consistent with the association of InvGE-6f [25]. One new association was found. The SNP allele InvGE- $A_{85}$ was positively associated (higher tuber starch content and starch yield) with TSC and TSY (Table 5). Haplotype analysis of 197 individuals using eight diagnostic SNPs in exon 1 identified 19 haplotypes found at frequencies greater than $1 \%$ in the ALL population (Table 7). Haplotypes $A$ and $B$ occurred at frequencies higher than $10 \%$ and accounted for $39 \%$ of all chromosomes in the population $(4 \times 197=788)$. Fourteen haplotypes with frequencies between $1 \%$ and $10 \%$ accounted for $60 \%$ of the chromosomes, including the associated alleles $S a$ and $D a$. Six haplotype models were compatible with cDNA sequences, whereas the remaining eleven haplotypes were new.

For InvGF, ten cDNA alleles were identified that coded for eight different amino acid sequences (Table 3, Table S4 in additional file 2, Figure S3 in additional file 9). Alignment of the cDNA alleles and InvGF from accession AJ133765 (cv Saturna, StinvGF-b) [21] revealed 99 SNPs, including three tri-allelic SNPs, which caused amino acid changes at 26 positions, corresponding to $4.5 \%$ of the deduced InvGF protein. Five similarity groups were distinguished. As in the case of $\operatorname{In} v G E$, group $a$ was the most divergent and group $d$ was the most heterogeneous. The $a$ and $d$ alleles of InvGE and InvGF might be part of the same haplotype block. The InvGF group $a$ alleles are therefore likely to correspond to the marker InvGF-4d.

\section{Natural diversity of InvCD141 and InvCD111 cDNA alleles} at the $\ln v_{a p}-a$ locus

Invertase cDNA alleles at the Inv $v_{a p}-a$ locus were cloned from leaf tissue. Fewer clones were sequenced than in the case of the loci Pain-1 and Invap-b. Twelve InvCD141 cDNA alleles (11 amino acid sequences) were represented among 28 sequences from six genotypes, and $9 \operatorname{InvCD111~cDNA}$ alleles (8 amino acid sequences) were obtained from 14 sequences of five genotypes (Table 3). Two additional alleles were found in the database: accessions Z21486 (cv Cara, StinvCD111-a) [19] and Z22645 (cv Cara, StinvCD141-d) [20]. One hundred and four SNPs (InvCD141) including three tri-allelic SNPs, and 71 SNPs (InvCD111) caused 32 and 36 amino acid changes, respectively, equivalent to 5-6\% protein diversity (Table 3, Tables S5 and S6 in additional files 3 and 4, Figures S4 and S5 in additional files 10 and 11). Grouping of the cDNA alleles according to similarity resulted in six and four groups for InvCD141 and InvCD111, respectively (Tables S5 and S6 in additional files 3 and 4). Sequencing of the amplified exon 3 of InvCD141 in the ALL population allowed us to score 38 SNPs. SNPs specific for the cDNA allele $\mathrm{Sa}\left(\mathrm{A}_{280}\right.$, $\left.\mathrm{T}_{288}, \mathrm{~T}_{339}, \mathrm{~T}_{543}, \mathrm{~A}_{630}, \mathrm{C}_{1030}, \mathrm{G}_{1031}, \mathrm{~T}_{1096}\right)$ were all in high linkage disequilibrium with each other. The presence/absence of this $\mathrm{Sa}$-specific haplotype (Table S5 in additional file 3 ) in the ALL population corresponded nearly perfectly to the associated SSCP marker $p C D 141$ $3 c$ (Jaccard similarity measure 0.92 ), indicating that the cDNA allele $S a$ corresponds to $p C D 141-3 c$. Association analysis of the SNPs confirmed $S a$ as an allele that is negatively associated with chip quality and tuber starch content. In addition, one novel, positive association of InvCD141-G $G_{765}$ with CQS, TSC and TSY was detected 
Table 6 Pain-1 haplotype models obtained with Satlotyper.

\begin{tabular}{|c|c|c|c|c|c|c|c|c|c|c|c|c|c|}
\hline Haplotype & $\begin{array}{l}\text { cDNA allele or } \\
\text { group } 1\end{array}$ & $\begin{array}{l}\text { Haplotype } \\
\text { frequency }\end{array}$ & $\begin{array}{l}\text { SNP } \\
528(b)^{2}\end{array}$ & $\begin{array}{l}\text { SNP } \\
552(a)\end{array}$ & $\begin{array}{l}\text { SNP } \\
612(c, d)\end{array}$ & $\begin{array}{l}\text { SNP } \\
637(d)\end{array}$ & $\begin{array}{l}\text { SNP } 639 \\
\text { (Stpain1-a) }\end{array}$ & $\begin{array}{l}\text { SNP } \\
718(a)\end{array}$ & $\begin{array}{l}\text { SNP } \\
741(\mathrm{Sa} a)\end{array}$ & $\begin{array}{l}\text { SNP } \\
825(x)\end{array}$ & $\begin{array}{l}\text { SNP } 1050 \\
(P 18 b)\end{array}$ & $\begin{array}{l}\text { SNP } \\
1068 \text { (c) }\end{array}$ & $\begin{array}{l}\text { SNP } \\
1544(a)\end{array}$ \\
\hline A & P18b & 0.295 & A & $\mathrm{T}$ & A & A & C & G & C & $\mathrm{T}$ & $\mathrm{T}$ & C & C \\
\hline B & $b$ & 0.173 & A & T & A & A & C & G & C & $\mathrm{T}$ & C & C & C \\
\hline
\end{tabular}


Table 7 InvGE haplotype models obtained with Satlotyper.

\begin{tabular}{|c|c|c|c|c|c|c|c|c|c|c|}
\hline Haplotype & $\begin{array}{l}\text { CDNA allele or } \\
\text { group } 1\end{array}$ & $\begin{array}{l}\text { Haplotype } \\
\text { frequency }\end{array}$ & $\begin{array}{l}\text { SNP } 85 \\
(a, d)^{2}\end{array}$ & $\begin{array}{l}\text { SNP } 89 \\
(x)\end{array}$ & $\begin{array}{l}\text { SNP } 106 \\
(S a, D a)\end{array}$ & $\begin{array}{l}\text { SNP } \\
108(b)\end{array}$ & $\begin{array}{l}\text { SNP } 132 \\
\text { (StinvGE-c) }\end{array}$ & $\begin{array}{l}\text { SNP } 133 \\
(T f)\end{array}$ & $\begin{array}{l}\text { SNP } 135 \\
(T a, S d)\end{array}$ & $\begin{array}{l}\text { SNP } 162 \\
(T d)\end{array}$ \\
\hline$A$ & Se and $c$ & 0.265 & G & $T$ & A & $T$ & $T$ & G & $T$ & $T$ \\
\hline B & $b$ & 0.121 & G & $\mathrm{T}$ & A & A & $\mathrm{T}$ & G & $\mathrm{T}$ & $\mathrm{T}$ \\
\hline C & Tf & 0.099 & G & $\mathrm{T}$ & A & $\mathrm{T}$ & $\mathrm{T}$ & C & $\mathrm{T}$ & $\mathrm{T}$ \\
\hline D & $T a$ and $d$ & 0.085 & $A^{*}$ & $T$ & A & $\mathrm{T}$ & $\mathrm{T}$ & G & A & $\mathrm{T}$ \\
\hline$E$ & & 0.057 & $A^{*}$ & $T$ & A & A & $T$ & G & $T$ & $T$ \\
\hline$F$ & & 0.043 & G & $\mathrm{T}$ & A & $\mathrm{T}$ & $T$ & G & A & $\mathrm{T}$ \\
\hline G & & 0.042 & $A^{*}$ & $\mathrm{~T}$ & A & $T$ & $\mathrm{~T}$ & G & $T$ & $\mathrm{~T}$ \\
\hline H & & 0.039 & G & $\mathrm{T}$ & $\mathrm{G}^{*}$ & $\mathrm{~T}$ & $\mathrm{~T}$ & G & $\mathrm{T}$ & $\mathrm{T}$ \\
\hline 1 & & 0.037 & G & A & A & $\mathrm{T}$ & $\mathrm{T}$ & C & $T$ & $\mathrm{~T}$ \\
\hline K & & 0.027 & $A^{*}$ & $\mathrm{~T}$ & A & A & $\mathrm{T}$ & G & A & $\mathrm{T}$ \\
\hline L & Sa and Da & 0.025 & $A^{*}$ & $T$ & $\mathrm{G}^{*}$ & $T$ & $T$ & G & $T$ & $\mathrm{~T}$ \\
\hline $\bar{M}$ & & 0.024 & G & T & A & A & $\mathrm{T}$ & C & $\mathrm{T}$ & $\mathrm{T}$ \\
\hline $\bar{N}$ & & 0.024 & G & A & A & A & $\mathrm{T}$ & G & $T$ & $\mathrm{~T}$ \\
\hline 0 & & 0.020 & $A^{*}$ & A & A & $T$ & $T$ & G & $T$ & $T$ \\
\hline$P$ & & 0.019 & G & $T$ & $\mathrm{G}^{*}$ & A & $T$ & G & $T$ & $\mathrm{~T}$ \\
\hline Q & & 0.015 & G & A & A & $T$ & A & G & $T$ & $T$ \\
\hline$R$ & $T d$ & 0.014 & $A^{*}$ & T & $A$ & $\mathrm{~T}$ & T & G & $\mathrm{T}$ & G \\
\hline$S$ & & 0.014 & $A^{*}$ & A & $A$ & A & A & G & A & $\mathrm{T}$ \\
\hline$T$ & & 0.012 & $\mathrm{G}$ & $T$ & $A$ & $\mathrm{~T}$ & $T$ & $G$ & $T$ & G \\
\hline
\end{tabular}

${ }^{1}$ cDNA allele or allele group that corresponds to the haplotype.

2 cDNA allele or allele group, for which the SNP is diagnostic (see Table S3 in additional file 1).

Associated SNP alleles are highlighted by *.

(Table 5). Haplotype modeling based on 192 individuals and ten SNPs resulted in 18 InvCD141 haplotype models (Table 8 ) with frequencies above 1\%. Two haplotypes with frequencies higher than $10 \%$ accounted for $27 \%$ of all chromosomes in the population $(4 \times 192=768)$, whereas the remaining 16 haplotypes with frequencies between $1 \%$ and $10 \%$ accounted for $74 \%$ of the chromosomes. Four haplotype models were compatible with cDNA alleles, including the associated allele $\mathrm{Sa}$ (haplotype $E$ ), whereas the remaining 14 haplotypes were new.

\section{Phylogenetic analysis of putative invertase proteins}

A phylogenetic tree was constructed based on the amino acid sequences deduced from 46 full-length cDNA sequences of Pain-1, InvGE, InvGF, InvCD141 and InvCD111 (S. tuberosum) and seven tomato invertase genes from S. lycopersicum and S. pennellii (Figure 2). The tree clearly showed five major branches corresponding to the five invertase genes from potato. With the exception of SlLIN9 (CAJ19056), which formed a sixth branch, the tomato genes Slpain1-a (AAB30874), SpLIN5- $a$ (CAB85898), SlLIN5- $a$ (CAB85897), SlLIN7- $a$ (AAM22410), SlLIN6-a (BAA33150) and SlLIN8-a (AAM28822) clustered with the respective orthologous potato genes. The interspecific distances between potato and tomato invertases were larger than the intraspecific distances between potato invertase alleles. Pain-1 was more closely related to the gene pair InvCD111/ $\operatorname{In} \nu C D 141$ than to $\operatorname{In} v G E / \operatorname{In} v G F$.

\section{Discussion}

Analysis of 193 cDNA sequences obtained from three tetraploid and three diploid potato genotypes revealed a high level of natural allelic variation in five potato invertase genes. Fifty-five different full-length cDNA sequences were identified, none of which were previously represented in the databases. Most were genotype specific: only nine were isolated from more than one of the cultivars examined. The average SNP density in cultivated potato is one SNP per 21-24 bp [41,42]. The genes Pain-1 and InvCD111 fell within this range with one SNP per 24 and $25 \mathrm{bp}$, respectively. The highest variability, with one SNP per $13 \mathrm{bp}$, was observed in the InvGE gene. InvGF and InvCD141, both with one SNP per $17 \mathrm{bp}$, also had higher than average variability. A total of 479 SNPs were detected, and nine (1.6\%) were tri-allelic. The 55 identified sequence variants represent a minimum estimate of the number of invertase alleles present in the six genotypes. Other alleles may have been missed due to template bias during PCR amplification [40] or because sample sizes were small, e.g. InvCD141 and InvCD111 in some genotypes. The sequence variants encode 46 distinct invertase proteins 
Table 8 InvCD141 haplotype models obtained with Satlotyper.

\begin{tabular}{|c|c|c|c|c|c|c|c|c|c|c|c|c|}
\hline Haplotype & $\begin{array}{l}\text { CDNA allele } \\
\text { or group }{ }^{1}\end{array}$ & $\begin{array}{l}\text { Haplotype } \\
\text { frequency }\end{array}$ & $\begin{array}{l}\text { SNP } 280 \\
(\mathrm{Sa})^{2}\end{array}$ & $\begin{array}{l}\text { SNP } 426 \\
(\mathrm{Sa}, \mathrm{Td} 3)\end{array}$ & $\begin{array}{l}\text { SNP } \\
440 \\
\text { (d) }\end{array}$ & $\begin{array}{l}\text { SNP } \\
543 \\
\text { (Sa) }\end{array}$ & $\begin{array}{l}\text { SNP } \\
673 \\
(\mathrm{Se})\end{array}$ & $\begin{array}{l}\text { SNP } \\
765 \\
\text { (e) }\end{array}$ & $\begin{array}{l}\text { SNP 862 } \\
(P 18 e, S e)\end{array}$ & $\begin{array}{l}\text { SNP } \\
889 \\
\text { (d) }\end{array}$ & $\begin{array}{l}\text { SNP } \\
1029 \\
(S b)\end{array}$ & $\begin{array}{l}\text { SNP } \\
1030 \\
(\mathrm{Sa})\end{array}$ \\
\hline A & d & 0.169 & G & $\mathrm{T}$ & G & $C$ & $A$ & A & A & C & $T$ & G \\
\hline$B$ & P54e1, P54e2 & 0.101 & G & $T$ & $C$ & $C$ & A & $\mathrm{G}^{*}$ & A & A & $T$ & G \\
\hline$C$ & & 0.086 & G & $T$ & $C$ & $C$ & G & A & G & A & $T$ & G \\
\hline D & & 0.073 & G & $\mathrm{T}$ & C & C & G & $\mathrm{G}^{*}$ & G & A & G & G \\
\hline$E$ & $\mathrm{Sa}$ & 0.064 & $A^{*}$ & C & C & $T^{*}$ & $A$ & A & $A$ & A & $T$ & C \\
\hline $\mathrm{F}$ & & 0.060 & $G$ & $T$ & G & $C$ & $A$ & $\mathrm{G}^{*}$ & $A$ & $A$ & $T$ & $G$ \\
\hline $\mathrm{G}$ & P18c & 0.060 & G & $T$ & $C$ & $C$ & A & A & A & A & $T$ & G \\
\hline $\mathrm{H}$ & & 0.058 & G & $\mathrm{T}$ & C & $C$ & G & A & G & A & $G$ & G \\
\hline 1 & & 0.058 & G & $T$ & $C$ & C & A & $\mathrm{G}^{*}$ & $A$ & C & $T$ & G \\
\hline K & & 0.048 & G & T & C & C & A & A & G & A & T & G \\
\hline L & & 0.047 & G & C & $C$ & $C$ & A & A & A & $C$ & $T$ & G \\
\hline $\bar{M}$ & & 0.047 & G & C & C & $C$ & G & $\mathrm{G}^{*}$ & $A$ & A & $\mathrm{G}$ & G \\
\hline N & & 0.038 & G & $\mathrm{T}$ & G & C & G & $\mathrm{G}^{*}$ & G & A & G & G \\
\hline $\mathrm{O}$ & & 0.027 & $G$ & $\mathrm{~T}$ & G & $\mathrm{T}^{*}$ & $A$ & A & A & A & $T$ & C \\
\hline$P$ & & 0.027 & $A^{*}$ & $T$ & C & $\mathrm{T}^{*}$ & A & A & $A$ & A & $T$ & $C$ \\
\hline Q & & 0.019 & G & $T$ & $C$ & C & G & A & A & A & $T$ & G \\
\hline$R$ & & 0.017 & $A^{*}$ & $T$ & $C$ & $\mathrm{~T}^{*}$ & G & $\mathrm{G}^{*}$ & G & A & $\mathrm{T}$ & C \\
\hline S & & 0.016 & $A^{*}$ & $C$ & G & $C$ & $A$ & $A$ & A & $C$ & T & G \\
\hline
\end{tabular}

${ }^{1}$ cDNA allele or allele group that corresponds to the haplotype.

2 cDNA allele or allele group, for which the SNP is diagnostic (see Table S5 in additional file 3).

Associated SNP alleles are highlighted by *.

that differ from each other by between 4 and $9 \%$. We took various precautions to eliminate sequence variants resulting from mistakes in reverse transcription or PCR. High-fidelity $T a q$ polymerases were used to minimize PCR-derived errors, and cDNAs were cloned from different PCR reactions. Three quarters of the cDNA alleles were supported by at least two cDNA sequences, and alleles were defined based on consensus sequences of all cDNA clones derived from an individual genotype, eliminating singletons (SNPs occurring only once in the multiple sequence alignments). Although we cannot prove that all of the 479 SNPs are authentic, it is highly unlikely that more than a tiny minority of the SNPs observed were generated in the test tube. The generally high level of DNA polymorphism in the genome of Solanum tuberosum is well documented $[29,33,41,42]$. However, very few data are available on the range of natural allelic variation among specific potato genes, particularly across multiple genotypes as studied here. Usually, potato genes are cloned and functionally characterized in a single cultivar. However, five different full-length cDNA clones encoding potato allene oxide synthase 2 (StAOS2) have been cloned from three diploid genotypes and functionally characterized [43]. High sequence variability has also been observed among genuine cDNA clones encoding Kunitz-type inhibitors in two tetraploid varieties [44]. The reason for this high genetic plasticity of the cultivated potato can be found in its reproductive biology. Potatoes are clonally propagated on an annual cycle. At much larger intervals (on the order of decades), the vegetative cycle is interrupted by sexual reproduction in the context of breeding programs. These combine heterozygous parental clones, select recombinant seedlings and propagate them again clonally. Switching between clonal and sexual reproduction may have been exploited during potato domestication and evolution, when farmers observed and selected in the field spontaneous hybrid seedlings among their clonally propagated crop [45]. In such a reproductive system, somatic mutations occurring at random during clonal propagation can give rise to cell lineages that eventually enter the germ line. Clonal selection will remove deleterious and favor beneficial somatic mutations [45]. The buffering capacity of a tetraploid genome may also allow the propagation of recessive deleterious mutations. The potato genome therefore represents a rich natural reservoir of mutant genes. In this respect, the potato genome stands in sharp contrast to the genome of its close relative the tomato (Solanum lycopersicum). The two genomes are highly colinear, but tomato shows very little intraspecific variation [46]. In contrast to potato, tomato is self-compatible and is propagated 


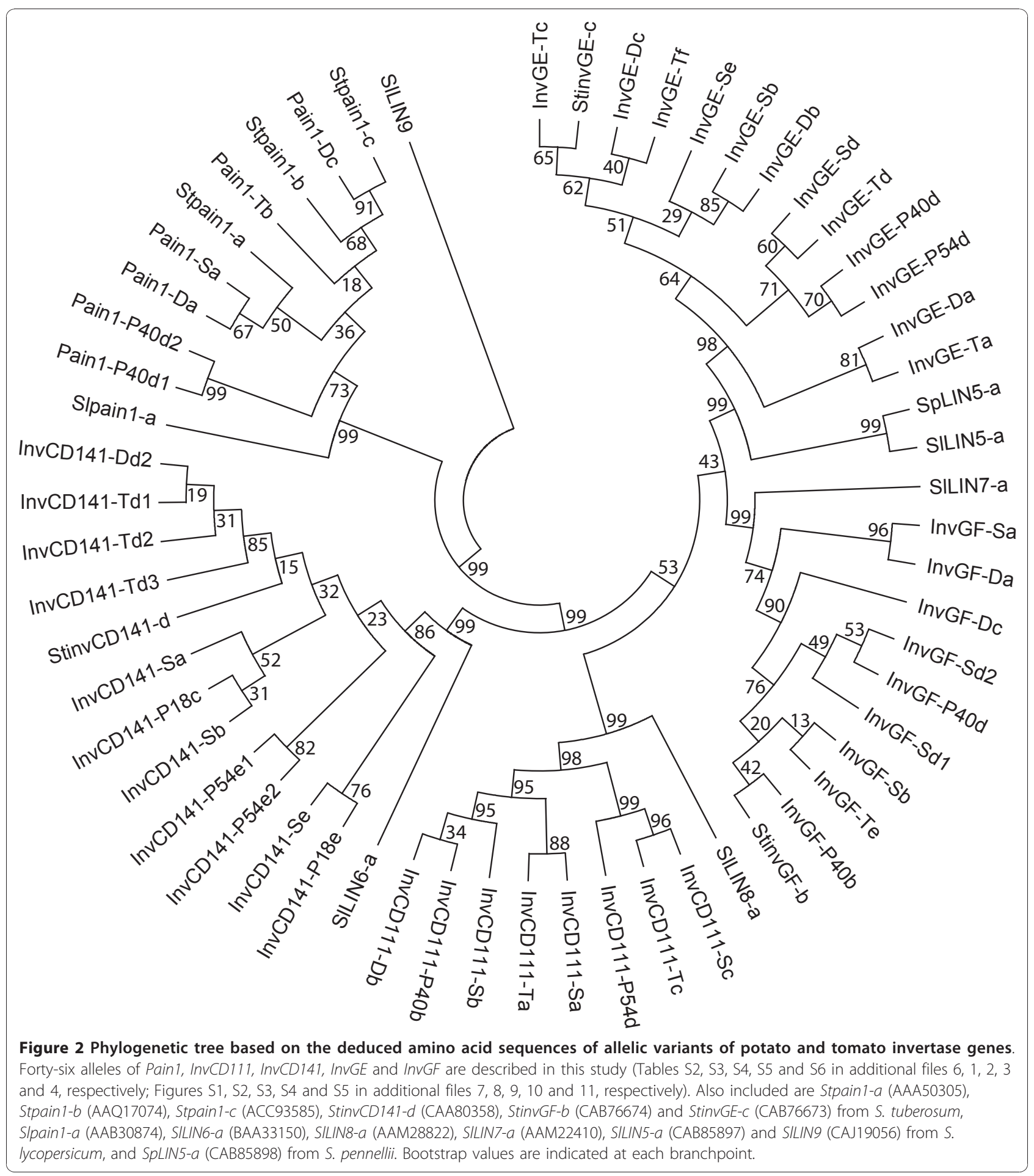

exclusively via seeds. Comparative functional characterization of natural potato invertase alleles - which is now possible, promises to uncover some interesting structure-function relationships. Functional differences between the coding regions of potato invertase alleles may be uncovered by the complementation of a yeast invertase mutant and the biochemical characterization of the heterologous expressed proteins [28]. Differences in the expression of alleles can be detected by quantifying the expression based on allele specific SNPs and pyrosequencing technology (Draffehn et al., manuscript in preparation). 
The work reported here was designed to identify fulllength cDNA clones encoding invertase alleles that are associated with chip quality, tuber starch content and starch yield [25] for further functional analysis. This goal was achieved for the associated markers Pain1-9a, Pain1-8c, InvGE-6f/InvGF-4d and $p C D 141-3 c$, but not for Pain1-5b and Pain1-5c, perhaps because an insufficient number of cDNA clones was analyzed. Alternatively, these SSCP markers might result from intron polymorphism that is not detectable in cDNA sequences. The full range of invertase alleles present in a population of 219 tetraploid individuals can be captured by genotyping 15, 11 and 38 SNPs, respectively, at the three invertase loci. Association analysis of the SNPs identified two new associations, one between the SNP allele InvGE- $A_{85}$ and TSC and TSY, and the other

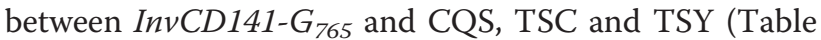
5). The Pain1- $a$ alleles showed the most significant and positive effects on chip quality and tuber starch content. The corresponding SSCP markers also show epistatic interactions with other candidate loci, which increase starch yield [47]. However, the frequency of these alleles in the ALL population was less than $10 \%$. Enrichment of Pain1- $a$ alleles in breeding populations should facilitate the selection of cultivars with improved quality traits. Interestingly, the three SNPs diagnostic for Pain-1 alleles of group a $\left(C_{552}, A_{718}\right.$ and $\left.A_{1544}\right)$ differed in their associations. These SNPs are in strong but not absolute linkage disequilibrium with each other. Pain1$C_{552}$ and Pain1- $A_{718}$ were more strongly associated with chip quality after cold storage, whereas Pain1- $A_{1544}$ was mainly associated with tuber starch content. Whereas the cDNA alleles Pain1-Da, Sa and P18a contained all three SNPs, the allele StPain1-a (AAA50305) contained only $A_{1544}$. This and the four different haplotype models obtained for these three SNPs (haplotypes $K, M, N, O$, Table 6) suggest further structural and possibly functional differentiation between the associated Pain1-a alleles, which may be exploitable for marker-assisted selection. Pain1-snp552 causes a synonymous nucleotide change, whereas Pain1-snp718 and Pain1-snp1544 induce non-synonymous changes. Pain1-SNP1544 causes the non-conservative amino acid change Thr515Lys. Whether these differences between the coding sequences or differences in the corresponding promoter regions are causal for possibly functional variation remains to be elucidated.

The direct inference of haplotypes from amplicon sequences requires that loci be homozygous, which is rarely the case in diploid and tetraploid potato genotypes. In amplicon sequences derived from heterozygous loci, the phase of the SNPs is unknown. The SATlotyper software was developed to model haplotypes in polyploid species based on unphased SNP data [40]. Haplotype modeling with a subset of the SNPs scored in the invertase genes Pain-1, InvGE and InvCD141 resulted for each gene in two or three haplotypes with higher frequencies (above 10\%) and a large number of minor haplotypes with low frequencies. This haplotype distribution might be typical for nuclear genes of the European potato and a signature of its domestication, introduction and breeding history [48-50]. More genes must be analyzed however, before any general conclusions can be drawn. The occurrence of numerous lowfrequency haplotypes is compatible with introgressions from other tuber-bearing Solanum species during $20^{\text {th }}$ century breeding programs [50] and/or sequence diversification due to fixation of somatic mutations as outlined above. The SNP information will be useful for tracing specific haplotypes back to their origin.

Haplotype modeling correctly predicted some, but not all cDNA alleles that were obtained experimentally from the cvs Satina, Diana and Theresa and could have been detected based on the chosen SNP set. This is because, based on the analysis of sequence trace files, the SNP allele dosage cannot be scored with complete accuracy in all individuals used for haplotype modeling. A small percentage of scoring errors leads to haplotype artefacts with low frequency. To eliminate such artefacts, we considered only haplotype models with a frequency above $1 \%$. As this is an arbitrary threshold, we cannot exclude the possibility that some of the remaining low-frequency haplotypes are also artefacts. Nevertheless, our results demonstrate that SATlotyper is a valuable tool for the fast identification of the major haplotypes present in populations of tetraploid potatoes. The determination of the exact haplotype composition of a tetraploid individual, including rare haplotypes, calls for an allele cloning approach such as that performed in this study.

As in tomato [22], the four genes encoding cell wallbound acidic invertases in potato are organized in two pairs of tandemly duplicated genes on chromosomes IX and X. The soluble acid invertase is encoded by a single gene on potato chromosome III. The existence of a sixth potato invertase gene is predicted, which is orthologous to the tomato gene SILIN9 located on chromosome 8 (based on the draft genome sequence of tomato provided by "The International Tomato Genome Sequencing Consortium" available at http://solgenomics. net and on personal communication from Gisella Orjeda, Universidad Peruana Cayetano Heredia, Peru). This gene might encode a soluble neutral invertase not characterized so far in potato. The five characterized potato invertase genes are all located within segmental chromosome duplications of unknown size, which show structural conservation with other, distantly related 
plant species [51,52]. Functionally essential parts of an ancestral plant genome might be preserved in such conserved chromosome segments. The important role invertases play in many aspects of plant life is consistent with their location in evolutionarily ancient parts of plant genomes.

\section{Conclusions}

Very high natural allelic variation in five potato invertase genes was uncovered by sequence analysis of full length cDNA clones from six different genotypes and SNP analysis in a larger association mapping population. This variability is explained by the potato's reproductive biology. Some of the structural variation found might be causal for functional variation, which influences important agronomic traits of the potato such as tuber starch and sugar content. The invertase cDNA clones described here are the basis for further functional studies. The associations found between specific invertase alleles and tuber starch content, starch yield and chip quality facilitate the selection of superior potato genotypes in breeding programs. Finally, our results point out that natural variation should be taken into account when conducting molecular and functional characterization of potato genes.

\section{List of abbreviations}

ASA: allele specific amplification; BAC: Bacterial artificial chromosome; CQA: Chip quality in autumn; CQS: Chip quality after storage at $4^{\circ} \mathrm{C}$; LD: linkage disequilibrium; PCR: Polymerase chain reaction; QTL: Quantitative trait locus; SCAR: sequence characterized amplified region; SSCP: single strand conformation polymorphism; TSC: tuber starch content; TSY: tuber starch yield; TY: tuber yield.

\section{Additional material}

Additional file 1: Table S3: SNPs differentiating InvGE CDNA alleles Additional file 2: Table S4: SNPs differentiating InvGF CDNA alleles. Additional file 3: Table S5: SNPs differentiating InvCD141 cDNA alleles

Additional file 4: Table S6: SNPs differentiating InvCD111 CDNA alleles.

Additional file 5: Table S1: Annotation of BAC clones BC149o15 and BC163l15

Additional file 6: Table S2: SNPs differentiating Pain-1 cDNA alleles.

Additional file 7: Figure S1: Amino acid alignment of Pain-1 CDNA alleles.

Additional file 8: Figure S2: Amino acid alignment of InvGE CDNA alleles.

Additional file 9: Figure S3: Amino acid alignment of InvGF CDNA alleles.

Additional file 10: Figure S4: Amino acid alignment of InvCD141 cDNA alleles.

Additional file 11: Figure S5: Amino acid alignment of InvCD111 cDNA alleles.

\section{Acknowledgements}

This work was carried out in the Department of Plant Breeding and Genetics headed by Maarten Koornneef and was funded by the Max-Planck Society. The authors thank Ulrike Göbel and Alexander Kerner for help with BAC annotation.

\section{Authors' contributions}

$\mathrm{AD}$ carried out the CDNA cloning, the sequence analyses and the haplotype modeling, and participated in the SNP analysis. SM performed the SNP analysis and contributed to the association statistics and haplotype modeling. LL carried out the pyrosequencing. CG conceived the study, participated in its design and coordination, carried out statistical analyses and drafted the manuscript. All authors read and approved the final manuscript.

Received: 2 September 2010 Accepted: 9 December 2010 Published: 9 December 2010

\section{References}

1. Roitsch T, González M-C: Function and regulation of plant invertases: sweet sensations. Trends in Plant Science 2004, 9(12):606-613.

2. Tymowska-Lalanne Z, Kreis M, Callow JA: The Plant Invertases: Physiology, Biochemistry and Molecular Biology. In Advances in Botanical Research. Volume 28. Academic Press; 1998:71-117.

3. Isherwood FA: Starch-sugar interconversion in Solanum tuberosum. Phytochemistry 1973, 12:2579-2591.

4. Sowokinos J: Biochemical and molecular control of cold-induced sweetening in potatoes. American Journal of Potato Research 2001, 78(3):221-236.

5. Müller-Thurgau H: Über Zuckeranhäufung in Pflanzentheilen in Folge niederer Temperatur. Landwirtsch Jahrb 11 1882, 751-828.

6. Richardson DL, Davies HV, Ross HA, Mackay GR: Invertase activity and its relation to hexose accumulation in potato tubers. J Exp Bot 1990 41(1):95-99.

7. Pressey R: Role of invertase in accumulation of sugars in cold stored potatoes. Am Pot J 1969, 46:291-297.

8. Pressey R, Shaw R: Effect of temperature on invertase, invertase inhibitor, and sugars in potato tubers. Plant Physiol 1966, 41:1657-1661.

9. Bagnaresi P, Moschella A, Beretta O, Vitulli F, Ranalli P, Perata P. Heterologous microarray experiments allow the identification of the early events associated with potato tuber cold sweetening. BMC Genomics 2008, 9(1):176.

10. Zrenner R, Schüler K, Sonnewald U: Soluble acid invertase determines the hexose-to-sucrose ratio in cold-stored potato tubers. Planta 1996, 198(2):246-252.

11. Zhou D, Mattoo A, Li N, Imaseki H, Solomos T: Complete nucleotide sequence of potato tuber acid invertase cDNA. Plant Physiology 1994, 106:397-398

12. Habib A, Brown HD: The role of reducing sugars and amino acids in browning of potato chips. Food Technol 1957, 11:85-89.

13. Townsend LR, Hope GW: Factors influencing the color of potato chips. Can J Plant Sci 1960, 40:58-64.

14. Frommer WB, Sonnewald U: Molecular analysis of carbon partitioning in solanaceous species. J Exp Bot 1995, 46(287):587-607.

15. Schäfer-Pregl R, Ritter E, Concilio L, Hesselbach J, Lovatti L, Walkemeier B, Thelen H, Salamini F, Gebhardt C: Analysis of quantitative trait loci (QTLs) and quantitative trait alleles (QTAs) for potato tuber yield and starch content. Theor Appl Genet 1998, 97(5):834-846.

16. Menendez CM, Ritter E, Schäfer-Pregl R, Walkemeier B, Kalde A, Salamini F, Gebhardt C: Cold sweetening in diploid potato: mapping quantitative trait loci and candidate genes. Genetics 2002, 162(3):1423-1434.

17. Chen X, Salamini F, Gebhardt C: A potato molecular-function map for carbohydrate metabolism and transport. Theor Appl Genet 2001, 102(2):284-295.

18. Gebhardt C, Menendez C, Chen X, Li L, Schäfer-Pregl R, Salamini F: Genomic approaches for the improvement of tuber quality traits in potato. Acta Hort 2005, 684:85-92, 85-92.

19. Hedley PE, Machray GC, Davies HV, Burch L, Waugh R: cDNA cloning and expression of a potato (Solanum tuberosum) invertase. Plant Mol Biol 1993, 22(5):917-922. 
20. Hedley PE, Machray GC, Davies HV, Burch L, Waugh R: Potato (Solanum tuberosum) invertase-encoding cDNAs and their differential expression. Gene 1994, 145(2):211-214.

21. Maddison AL, Hedley PE, Meyer RC, Aziz N, Davidson D, Machray GC: Expression of tandem invertase genes associated with sexual and vegetative growth cycles in potato. Plant Molecular Biology 1999, 41(6):741-752.

22. Fridman $E$, Zamir D: Functional divergence of a syntenic invertase gene family in tomato, potato, and Arabidopsis. Plant Physiol 2003, 131(2):603-609.

23. Bonierbale MW, Plaisted RL, Tanksley SD: RFLP Maps Based on a Common Set of Clones Reveal Modes of Chromosomal Evolution in Potato and Tomato. Genetics 1988, 120(4):1095-1103.

24. Orita M, Suzuki Y, Sekiya T, Hayashi K: Rapid and sensitive detection of point mutations and DNA polymorphisms using the polymerase chain reaction. Genomics 1989, 5:874-879.

25. Li L, Paulo MJ, Strahwald J, Lübeck J, Hofferbert HR, Tacke E, Junghans H, Wunder J, Draffehn A, van Eeuwijk F, et al: Natural DNA variation at candidate loci is associated with potato chip color, tuber starch content, yield and starch yield. Theor App/ Genet 2008, 116:1167-1181.

26. Li L, Strahwald J, Hofferbert HR, Lübeck J, Tacke E, Junghans H, Wunder J, Gebhardt C: DNA variation at the invertase locus invGE/GF is associated with tuber quality traits in populations of potato breeding clones. Genetics 2005, 170(2):813-821.

27. Hirschhorn JN, Daly MJ: Genome-wide association studies for common diseases and complex traits. Nat Rev Genet 2005, 6(2):95-108.

28. Fridman E, Carrari F, Liu Y-S, Fernie AR, Zamir D: Zooming in on a quantitative trait for tomato yield using interspecific introgressions. Science 2004, 305(5691):1786-1789.

29. Gebhardt C, Ritter E, Debener T, Schachtschabel U, Walkemeier B, Uhrig H, Salamini F: RFLP analysis and linkage mapping in Solanum tuberosum. Theor Appl Genet 1989, 78:65-75.

30. Hanahan D: Studies on transformation of Escherichia coli with plasmids. $J$ Mol Biol 1983, 166:557-580.

31. Sambrook J, Russell DW: Molecular cloning. A laboratory manual. New York: Cold Spring Harbor Lab. Press; 32001.

32. Ballvora A, Ercolano MR, Weiss J, Meksem K, Bormann CA, Oberhagemann P, Salamini F, Gebhardt C: The R1 gene for potato resistance to late blight (Phytophthora infestans) belongs to the leucine zipper/NBS/LRR class of plant resistance genes. Plant J 2002, 30(3):361-371.

33. Ballvora A, Jöcker A, Viehover $P$, Ishihara $H$, Paal J, Meksem K, Bruggmann $R$, Schoof H, Weisshaar B, Gebhardt C: Comparative sequence analysis of Solanum and Arabidopsis in a hot spot for pathogen resistance on potato chromosome $\mathrm{V}$ reveals a patchwork of conserved and rapidly evolving genome segments. BMC Genomics 2007, 8:112.

34. Margulies M, Egholm M, Altman WE, Attiya S, Bader JS, Bemben LA, Berka J, Braverman MS, Chen Y-J, Chen Z, et al: Genome sequencing in microfabricated high-density picolitre reactors. Nature 2005 437(7057):376-380.

35. Sanger F, Nicklen S, Coulson AR: DNA sequencing with chain-terminating inhibitors. Proc Natl Acad Sci USA 1977, 74(12):5463-5467.

36. Lewis SE, Searle SM, Harris N, Gibson M, Lyer V, Richter J, Wiel C, Bayraktaroglir L, Birney E, Crosby MA, et al: Apollo: a sequence annotation editor. Genome Biol 2002, 3(12):RESEARCH0082.

37. Larkin MA, Blackshields G, Brown NP, Chenna R, McGettigan PA, McWilliam H, Valentin F, Wallace IM, Wilm A, Lopez R, et al: Clustal W and Clustal X version 2.0. Bioinformatics 2007, 23(21):2947-2948.

38. Tamura K, Dudley J, Nei M, Kumar S: MEGA4: Molecular Evolutionary Genetics Analysis (MEGA) software version 4.0. Mol Biol Evol 2007, 24(8):1596-1599.

39. Ronaghi M, Karamohamed S, Petterson B, Uhlén M, Nyrén P: Real-time DNA sequencing using detection of pyro-phosphate release. Anal Biochem 1996, 242:84-89.

40. Neigenfind J, Gyetvai G, Basekow R, Diehl S, Achenbach U, Gebhardt C, Selbig J, Kersten B: Haplotype inference from unphased SNP data in heterozygous polyploids based on SAT. BMC Genomics 2008, 9(1):356.

41. Rickert AM, Kim JH, Meyer S, Nagel A, Ballvora A, Oefner PJ, Gebhardt C: First-generation SNP/InDel markers tagging loci for pathogen resistance in the potato genome. Plant Biotechnol J 2003, 1(6):399-410.
42. Simko I, Haynes KG, Jones RW: Assessment of linkage disequilibrium in potato genome with single nucleotide polymorphism markers. Genetics 2006, 173(4):2237-2245.

43. Pajerowska-Mukhtar KM, Mukhtar MS, Guex N, Halim VA, Rosahl S, Somssich IE, Gebhardt C: Natural variation of potato allene oxide synthase 2 causes differential levels of jasmonates and pathogen resistance in Arabidopsis. Planta 2008, 228(2):293-306.

44. Heibges A, Glaczinski H, Ballvora A, Salamini F, Gebhardt C: Structural diversity and organization of three gene families for Kunitz-type enzyme inhibitors from potato tubers (Solanum tuberosum L.). Mol Genet Genomics 2003, 269(4):526-534.

45. McKey D, Elias M, Pujol B, Duputié A: The evolutionary ecology of clonally propagated domesticated plants. New Phytologist 2010, 186(2):318-332

46. Miller JC, Tanksley SD: RFLP analysis of phylogenetic relationships and genetic variation in the genus Lycopersicon. Theor Appl Genet 1990, 80(4):437-448.

47. Li L, Paulo M-J, van Eeuwijk F, Gebhardt C: Statistical epistasis between candidate gene alleles for complex tuber traits in an association mapping population of tetraploid potato. Theor Appl Genet 2010, 121(7):1303-1310.

48. Ames M, Spooner DM: DNA from herbarium specimens settles a controversy about origins of the European potato. Am J Bot 2008, 95(2):252-257.

49. Spooner DM, McLean K, Ramsay G, Waugh R, GJ B: A single domestication for potato based on multilocus amplified fragment length polymorphism genotyping. Proc Natl Acad Sci USA 2005, 102(41):14694-14699.

50. Ross H: Potato breeding - problems and perspectives. Berlin and Hamburg: Paul Parey; 1986.

51. Dominguez I, Graziano E, Gebhardt C, Barakat A, Berry S, Arus P, Delseny M, Barnes S: Plant genome archaeology: evidence for conserved ancestral chromosome segments in dicotyledonous plant species. Plant Biotechnol J 2003, 1(2):91-99.

52. Gebhardt C, Walkemeier B, Henselewski H, Barakat A, Delseny M, Stuber K: Comparative mapping between potato (Solanum tuberosum) and Arabidopsis thaliana reveals structurally conserved domains and ancient duplications in the potato genome. Plant J 2003, 34(4):529-541.

doi:10.1186/1471-2229-10-271

Cite this article as: Draffehn et al:: Natural diversity of potato (Solanum tuberosum) invertases. BMC Plant Biology 2010 10:271.

\section{Submit your next manuscript to BioMed Central and take full advantage of:}

- Convenient online submission

- Thorough peer review

- No space constraints or color figure charges

- Immediate publication on acceptance

- Inclusion in PubMed, CAS, Scopus and Google Scholar

- Research which is freely available for redistribution

Submit your manuscript at www.biomedcentral.com/submit
C Biomed Central 